\title{
Significance of absence: The case of zero and empty morphs
}

\author{
Ingeborg M Kosch \\ Department of African Languages, University of South Africa, P O Box 392, Pretoria 0003, \\ Republic of South Africa \\ e-mail: koschim@unisa.ac.za
}

\begin{abstract}
The morpheme is generally understood as a unit which has form as well as content, i.e. a physical substance (phonological and phonetic) and a meaning or function within a grammatical system. With reference to examples from Northern Sotho and Zulu, this article demonstrates that zero morphs and empty morphs, as realizations of morphemes, fail to comply in one way or another with the above-mentioned characteristics posited for morphemes. Zero morphs lack a physical form, while empty morphs lack a meaning. These facts render the recognition of zero morphs and empty morphs somewhat controversial, but many linguists nevertheless find it convenient to identify such morphs in their analyses.
\end{abstract}

\section{Introduction}

Traditionally morphemes are defined as the smallest units of which words are composed and in which there is an arbitrary union of a sound and a meaning or function. Linguists do not all use the term morpheme in this sense; some distinguish another unit, namely the morph, when wanting to refer specifically to the phonological form of a morpheme. For example, Lockwood (1993:12-13) states: 'A morph ... is a sequence of phonemes which bears a meaning and cannot be divided into smaller meaning-bearing phoneme sequences.' The term morpheme is then relegated to an abstract status where its representation is merely a 'default' one and not the actual realization within a word. For example, the 'default' forms of the morphemes which constitute the word mmopi 'creator' in Northern Sotho are $\{$ mo- $\}$, $\{$-bop- $\}$ and $\{-i\}$. Within the actual word, morphemes may assume different phonological shapes, which are referred to as morphs, in this case $/ \mathrm{m}-/, /$-mop- $/$ and $/ \mathrm{i} /$ respectively. Each morph carries the same meaning or function as the morpheme which it represents, e.g. /m-/ indicates grammatical gender class 1 , as does the prefixal morpheme \{mo-\}; /-mop-/ expresses the lexical content 'create' just as $\{$-bop- $\}$ does; while /-i/ is a marker of a personal deverbative, just like the suffix $\{-\mathrm{i}\}$. This article endeavours to show that the recognition of certain morphs, such as zero and empty morphs, is somewhat controversial, due to the fact that they fail to display either a physical substance (sound properties) or a meaning. The nature of zero morphs and empty morphs is investigated with reference to examples from two African languages, namely Northern Sotho and Zulu.

In ideal agglutinative languages morphemes would occur in a one-to-one relationship with their morphs, which means that every abstract morpheme would correspond to a particular concrete morph. However, in most languages, even agglutinative ones such as Northern Sotho and Zulu, this one-to-one pattern is often deviated from, giving rise to the identification of various types of morphs such as zero and empty morphs, amongst others. Zero morphs are morphs which have a morphemic representation at the abstract level, but no phonological properties at the concrete level. Empty morphs are in a sense the converse of zero morphs in that they have phonological properties at the concrete level, but do not correspond to any morpheme (lexical or grammatical meaning) at the abstract level.

\section{Zero morphs}

A morph is generally defined as the phonological (or orthographical) representation of a morpheme (Lyons, 1968: 196). This means that a morph has an overt or concrete manifestation by which it can be recognized. Postulating a zero morph constitutes an anomaly, since zero implies no phonological substance, while morph implies a phonological representation. Lockwood (1993:45) proposes the use of the term zero allomorph rather than zero morph to resolve this anomaly. He explains that 'a morph is defined as consisting of phonemic material, so it cannot be zero. Nevertheless, one of the allomorphs of a morpheme may be zero, and we can view a zero allomorph as one which corresponds to no morph' (emphasis added). 
It is important to recognize that a morpheme may have a zero realization, i.e. the absence of a morph, as one of its allomorphs, but not as its only morph. If zero is the only morph, i.e. if there is never any form, we cannot set up a morpheme. For example, we cannot postulate a morpheme \{non-past\} for verb stems in the African languages, because 'non-past' is never marked by a special affix.

Although Lockwood (1993:45) states that a morph cannot be zero, while an allomorph can, we shall continue in this debate to make use of the more established term zero morph (alongside zero allomorph), bearing in mind Lockwood's clarification above.

A morph which consists of no phonemic material is customarily symbolized as a zero with a slash through it ( $\emptyset)$. The fact that this morph has no phonological manifestation does not make it irrelevant or meaningless, however. Its corresponding morpheme is indeed present in the underlying representation, and whether or not it has a concrete manifestation under certain conditions depends on the rules of grammar and phonology. In order to keep the statement of rules as simple as possible, the zero morph may be included in the concrete lay-out of a word, where it acts as a kind of 'place-holder' for a morph with the purpose of completing the regular structure.

In Zulu the preprefix of a noun generally has no physical realization when following a demonstrative pronoun. Consider the preprefix $a$ - of $a b a n t u$, which is deleted in ( $1 \mathrm{~b})$ :

(1a) uthanda abantu 'he likes people'

(1b) uthanda labo $\emptyset$ bantu 'he likes those people'

The zero morph preceding bantu in ( $\mathrm{lb}$ ) above is a syntactically conditioned variant of the preprefix, and it occurs in complementary distribution to its co-allomorph $a$-. In order to show that the regular structure of the class prefix in Zulu is bipartite, the place of the absent preprefix is filled by $\emptyset$ :

Figure 1: The zero morph $\emptyset$ : no phonological representation

$$
\begin{array}{lccc}
\text { morphemic level: } & \{\text { preprefix }\}+\{\text { basic prefix }\}+\{-\mathrm{ntu}\} \\
& \downarrow & \downarrow & \downarrow \\
\text { phonemic level: } & \emptyset & /-6 \mathrm{a}-/ & / \text {-ntu/ }
\end{array}
$$

Other cases where zero morphs may be postulated occur in the possessive construction in Zulu, among others. (This is discussed at length in Carstairs, 1987:169, 170.) When the possessor is a class la noun (e.g. ubaba'my father'), the prefix of the possessor is realized as zero, as shown in (2a). If the possession belongs to a class where the subject concord consists of a vowel only, the concordial prefix which precedes the possessive formative is also absent, as in (2b). In both examples the possessive formative realizes as $-k a$-instead of the regular - $a$-, because the possessor belongs to class $1 \mathrm{a}$ :

(2a) (isinkwa) sikababa 'my father's (bread)'

$$
\begin{aligned}
& \text { Morphemes: } \quad\{\mathrm{si}-\}+\{-\mathrm{a}-\}+\{\mathrm{u}-\}+\{\text {-baba }\} \\
& \text { Morphs: } \quad / \mathrm{si}-/+1-\mathrm{ka}-/+\emptyset+/-6 \mathrm{aba} /
\end{aligned}
$$

(2b) (umuzi) kababa 'my father's (homestead)'

$$
\begin{array}{lll}
\text { Morphemes: } & \{\mathrm{u}-\}+\{-\mathrm{a}-\}+\{\mathrm{u}-\}+\{\text {-baba }\} \\
\text { Morphs: } & \emptyset+1 \mathrm{ka}-1+\emptyset+\text { Haba }
\end{array}
$$

Brown and Miller (1991:179) state that 'Zero allomorphs are often postulated when the structure of a series of related forms is such that there is a "significant absence" of a formal marker at some point in the series.' Classical examples in English include the plural morpheme for sheep and the past tense morpheme for cut, which are both zero, the former in the series of allomorphs of the plural and the latter in the series of past tense suffixes. In these cases we can offer no reason for the occurrence of zero allomorphs other than that they are conditioned by the particular lexical item involved. In the following Northern Sotho examples, the presence of a zero prefix in certain class 9 nouns is determined, not by the lexical item, but by the fact that the nominal stem is polysyllabic. Nouns with monosyllabic stems, on the other hand, display the regular structure, i.e. prefix plus stem. Since it would be awkward to formulate an additional rule to accommodate nouns without an apparent prefix, it is convenient to say that the class prefix is indeed 'there', but in the form of a zero allomorph. In our statement of the structure of the noun the zero allomorph holds the place usually taken by the overt prefix. 

Basic prefix $\{\mathrm{N}-\}$
Allomorphs: [n-] before alveolars as in n-twa 'war'
[m-] before labials as in $m$-phô ' $\mathrm{gift}$ '
[n-] before palatals as in $n-t s h u$ 'eagle'
$[\mathrm{\eta}-\mathrm{]}$ before velars as in $n-k u$ 'sheep'
$\emptyset$ before polysyllabic stems as in tau 'lion', tlêmô 'condition of service', phedišanô 'neigh- bourliness'

In deverbatives where the first sound of the polysyllabic stem is determined by a process of occlusivation (e.g. tek $\hat{o}$ 'test' from -leka 'try', phapanô 'difference' from -fapana 'differ', etc.) two analyses are possible: On the one hand, the class prefix may be postulated as a zero morph (the same as for other polysyllabic class 9 noun stems, in which initial occlusivation is not applicable, as in kgôši 'king', for example). The class prefix exists only at some abstract underlying level and is considered to have disappeared completely from the concrete phonological level. On the other hand, the prefix may be regarded as still being present on the concrete phonological level. Supporting this view, Nida (1948 in Joos, 1963:268) states that the postulation of a zero morph does not do justice to the facts. Giving a comparable example from Yipounou (a Bantu language of Gabon), Nida claims that the prefix is not zero, but actually coincides with the second morpheme, since it has left its trace in the second morpheme by way of consonant modification.

Ferreira (1968:40) describes the causative morpheme in certain verb stems in the Sotho languages as a zero morpheme (e.g. Northern Sotho -theoga > -theoša 'bring down', -rwala > -rwêšsa 'cause to carry', -apara > -apêša 'clothe', etc.). It is true that neither the normal variant $\{-i \bar{s}-\}$ nor the alternant form $\{-\mathrm{Y}-\}$ of the causative morpheme is recognizable in any of these examples. This, however, does not mean that the causative morpheme can be labelled as zero. It has, after all, left a clear trace in the surface representations, as can be seen by the mutations in the verb stems.

It is evident that there is more than one way in which words may be analyzed, some analyses being more credible than others. The following, for example, are two of numerous possibilities which have been proposed by linguists for handling the plural form of man in English:

men is a morphemic alternant of man plus a zero alternant of the plural suffix, $O R$

men is one morph, which belongs simultaneously to two morphemes, namely $\{\operatorname{man}\}$ and $\{s\}$.

Bauer (1992:257) notes that 'analyses with zero morphs are always controversial, and that alternative analyses are always possible. Even if zero morphs are permitted in an analysis, care should be taken to avoid their proliferation.'

Brown and Miller (1980:181) also caution that zero should be used sparingly since it can lead to abuses. A zero morph for any morpheme can only be recognized on the strength of an overt realization of at least one other allomorph of the same morpheme in another environment. When dealing with zero morphs, a special criterion needs to be introduced, namely that no morpheme may be postulated which has only a zero morph. Without such a restriction the postulation of zero morphs could be stretched to ridiculous extremes. We could, for example, claim that a noun like Northern Sotho noka 'river' has zero morphs to mark its status as non-diminutive, non-augmentative and non-locative. However, there are no special affixes which at any time mark noka, or any nouns in the Bantu languages for that matter, as non-diminutive, non-augmentative or non-locative. Should such 'zero affixations' be included in the morphological description of a noun, it would render the statement of the rules extremely cumbersome and complex. Brown and Miller (1980:190) refer to cases in which a category is never marked by any morph as instances of null realization (as opposed to zero realization, where 'zero' implies a realization, but that the realization is $\emptyset$ ).

In Northern Sotho we may postulate a zero realization within the series of allomorphs which signal the property 'singular', e.g. in class 5 . Here zero is a co-allomorph of the prefix le-:
(4a) o timêtše lewatlêng
'he got lost at sea'
(lewatlê 'sea')

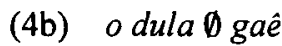
'he stays at home' ((le)gâ 'home')

In a language such as English the singular form is never marked by any specific morpheme. There would be no sense in identifying a zero morph in this case, since it cannot be contrasted with any overt representation of a 'singular marker'.

Subject concords, just like class prefixes, may in certain contexts have a zero realization, e.g. the subject concord in Zulu before the auxiliary verb stem -be: 
(5a) ngibengihamba >

(5b) bengihamba

'I was walking'

Nouns in Zulu are generally marked in two places to signify the locative, namely by a change in the preprefix (or only prefix, where only one prefix is present) and the addition of the locative suffix -ini, cf. (6a). Some items, however, do not display the second locative marker, cf. (6b):

$\begin{array}{llll}\text { (6a) indlu 'house' } & > & \text { endlini } & \text { 'at/in the house' } \\ \text { (6b) ubusuku 'night' } & > & \text { ebusuku } \varnothing & \text { 'at night' }\end{array}$

With regard to examples (4b), (5b) and (6b) we could say, in the words of Pike \& Pike (1977:187), that 'the meaning of a morpheme occurs even if an overt form of the morpheme does not occur', namely 'singular class 5 ', 'first person singular' and 'locative' respectively. Zero morphs are therefore meaningful even though they do not have a realization.

In discussing word category changes in English, e.g. from noun to verb as in an orbit versus to orbit, Spencer (1991:20) says that the change of category is the effect of attaching an affix, but that the affix happens to be phonologically null. He goes on to say that zero affixation 'is intended to be just like any other form of affixation. Here the morpheme responsible is clearly a thing, though a ghostly one'. In Northern Sotho, nouns which are employed as locative adverbs are usually marked by an affix, e.g. -ng in example (7c):

(7a) Motse o kgauswi le dithaba.

(7b) *Re dula motse lehôno.

(7c) Re dula motseng lehôno.
'The village is near mountains.'

(the noun motse functioning as the subject of the sentence)

'We are staying in the village today.' (the noun motse functioning as a locative adverb, in which case it is marked by the suffix $-n g$ )

However, in the case of certain nouns, no overt affix is employed to mark locality, cf. (8b):

(8a) Mošatê o kgauswi le dithaba.

(8b) Re dula mošatê lehôno.
'The chief's kraal is near mountains.'

(the noun mošatê functioning as the subject of the sentence)

'We are staying at the chief's kraal today.'

(the noun mošatê functioning as a locative adverb)

The reason why mošate does not require any additional marking when used as a locative adverb is that it has an inherent locative meaning, unlike motse, which lacks an inherent locative meaning and therefore needs to be marked overtly by means of the suffix -ng. The morphological element responsible for changing the meaning of the noun in (8a) (i.e. 'the chief's kraal') to a locative meaning in ( $8 \mathrm{~b}$ ) (i.e. 'at the chief's kraal') has no phonological properties on the concrete level. We may postulate a zero allomorph for the locativizing element in example (8b), because, as was explained earlier, zero is not the only realization, but a co-allomorph of at least one other concrete phonological realization (in the form of the suffix -ng) in another comparable environment, as shown in (7c). The ungrammaticality of a form such as *mošatêng and the grammaticality of motseng are determined by the specific lexical item involved.

Some linguists do not feel comfortable postulating a zero morph, because the places where zero morphs could be distinguished can theoretically be endless, e.g. a present tense form could be said to include a zero past tense form, etc. For this reason zero morphs are not universally recognized. Nevertheless, morphologists often find it convenient to resort to zero morphs in order to render certain structural descriptions in the simplest and most economical way possible and to reflect regularities in patterns (cf. Pearson, 1977:48, 107; Okoth Okombo in Webb \& Kembo-Sure, 2000:203).

\section{Empty morphs}

Unlike zero morphs, which have meaning but no phonological substance, empty morphs have phonological substance, but no meaning. 
Words cannot always be segmented consistently and where segments are identifiable, they do not always correspond to a morpheme. Empty morphs occur in situations in which there are too many morphs for the number of available morphemes. Segments which do not appear to belong properly to any morpheme are known as empty morphs. They appear as a residue between segments after all other segments have been accounted for morphologically and assigned to a morpheme (representative of a lexical meaning or grammatical function). Even though such residual segments do not correspond to any morpheme - and by implication have no lexical or grammatical content - they are still regarded as morphs, because they have a physical presence within a word. In describing empty morphs, Hockett (1947 in Joos, 1963:235) states that 'an utterance consists wholly of morphs: every bit of phonemic material in an utterance is part of one morph or another .... some of the morphs, and hence some bits of phonemic material, of some utterances, are morphemically irrelevant'.

In certain locative constructions in Zulu we may encounter an empty morph, i.e. a 'surplus' word-building element, which is introduced as a form of 'buffer' element to keep certain morphs apart, namely the formative $-s-$. It is meaning-deficient and not assigned to any morpheme, but it is required for purely morphological reasons. It occurs, for example, between the associative formative na- and locative forms with an initial vowel $e$ - as in:

endlini 'at the house'

$>$ nasendlini 'also at the house'

The following representation of the morphemic and phonemic levels illustrates that the morph /-s-/ has no slot in the linear sequence of morphemes at the abstract level, i.e. it is not formally featured as a morpheme here. It only appears at the concrete phonemic level.

Figure 2: The empty morph /-s-l: no morphemic representation

morphemic level: $\{$ associative formative $\}+\{$ locative $\}+\{$ class gender $\}+\{-$ dlu -$\}+\{$ locative $\}$

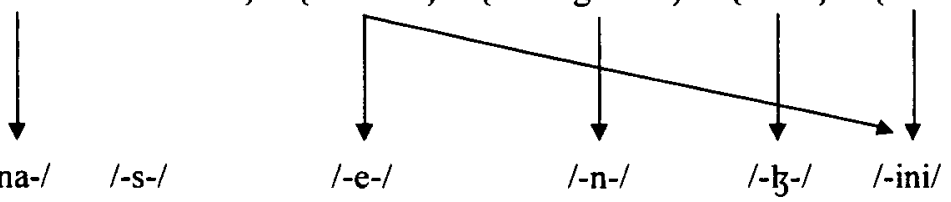

phonemic level: /na-l /-s-l $\quad /-\mathrm{e}-/ \quad /-\mathrm{n}-/ \quad /-\mathrm{l}-/ \quad /$-ini/

According to Anderson (1992:53-54), an empty morph, or subpart of a form that lacks any content whatsoever, is simply 'necessary morphological glue'.

Earlier on it was stated that zero morphs should rightly be referred to as zero allomorphs, since they are never the only realizations of a morpheme, but are always part of a paradigm of allomorphs. Empty morphs, however, are not allomorphs at all. Nevertheless they stil remain morphs, even though they realize no morpheme, cf. Matthews (1972:78), who states that an empthy morph 'is present in the phonological word-form but ..., unlike all normal morphs, fails to enter into the allomorph-relation.'

Empty morphs are therefore not members of a potential paradigm. They are mechanical by-products within specific environments and are unassociated with any morphemic content. However, their distribution can be accounted for phonologically or grammatically. When imperatives are formed from monosyllabic verb stems, the stem is usually marked by a segment (prefix or suffix) traditionally referred to as a 'stabilizer', e.g. Northern Sotho e- or - $a$ and Zulu $y i-/ w o-$ or -na. Even though the stabilizer cannot be matched with a particular morpheme, it is 'necessary morphological glue':

(10a) Northern Sotho:

(10b) Zulu:

$\begin{array}{ll}\text { etla! or tlaa! } & \text { 'come!' } \\ \text { yidla! or dlana! } & \text { 'eat!' } \\ \text { woza! } & \text { 'come!' }\end{array}$

Verb stems commencing with a vowel display empty morphs in the Sotho languages when they are preceded by the reflexive prefix (example lla) or the object concord of the first person singular (example 11b) or the class prefix of class 9 (example 11c). In these cases, the phoneme /-k-/ is inserted before the verb stem as an empty morph. It has no morphemic status: 
Northern Sotho:

Morphemes:

$$
\begin{aligned}
& \{-\mathrm{i}-\}+\{-\mathrm{arab}-\}+\{-\mathrm{a}\} \\
& \{-\mathrm{N}-\}+\{\text {-ape- }\}+\{-\hat{e} l-\}+\{-a\} \\
& \{\mathrm{N}-\}+\{-\hat{p} \text { êl- }\}+\{-o ̂\}
\end{aligned}
$$

Morphs:

As in the case of zero morphs, there is an anomaly inherent in the term 'empty morph'. By definition a morpheme is a unit of meaning and each of its morphs or allomorphs, as a physical realization of the morpheme, should have the same semantic content or grammatical function as the morpheme which it represents. An empty morph, however, has no meaning and belongs to no morpheme. The concept of the empty morph nevertheless proves to be a handy label for identifying otherwise unaccounted-for phonological fragments in words and phrases. In this case, the traditional notion of a morph is thus extended to include phonological segments which are not assigned to any morpheme.

\section{Conclusion}

An analysis which attempts to assign phonological segments exhaustively to morphemes will invariably be complicated by elements which cannot be accommodated within the ideal one-to-one patterning, i.e. there is not always a strict proportionate relationship between the morphological structure and a particular grammatical function or lexical content. Two elements which were targeted in this discussion are zero and empty morphs. They appear to be 'deficient', since they do not comply totally with the classical expectations of what a morph is. In order to summarize their 'deviant' character, we shall firstly examine the requirement of a physical representation and secondly the requirement of meaningfulness.

\section{Physical representation}

The term morph implies phonological properties, as expressed by Katamba (1993:24): 'A morph is a physical form representing some morpheme in a language. It is a recurrent distinctive sound (phoneme) or sequence of sounds (phonemes)'.

Empty morphs do have a physical form and thus comply with the above requirement. Zero morphs, however, have no concrete realization, and therefore reference to the term morph in this context constitutes an anomaly. It was indicated, however, that a morph may be zero on condition that it is part of a series of allomorphs, in other words, it may not constitute the only morph. It should appear as an allomorph of some morpheme which more commonly has an overt form, i.e. which displays at least one co-allomorph in parallel examples in a language. It would therefore be more correct to speak of a zero allomorph than of a zero morph, cf. Lockwood (1993:291): 'a morpheme may have zero - the absence of a morph - as one of its allomorphs'.

Just as allomorphs with phonological material 'realize' or 'make real' a particular morpheme, meaning or function, so the zero allomorph realizes a particular morpheme, meaning or function, except that it does not consist of phonological material. Its physical absence does not render it irrelevant in the structural statement of a particular word or utterance.

The definition of a morph as a phonological realization of a morpheme needs to be extended to include zero morphs. Hockett (1947 in Joos, 1963:240) proposes that it would perhaps be advisable to distinguish terminologically between 'primary morphs' (those with overt phonemic content) and 'extended morphs' (including primary ones and morphs of the zero, replacement or subtraction types).

\section{Meaningfulness}

A morpheme is by definition a unit of meaning. Therefore each allomorph of a morpheme has the same meaning (cf. Pearson, 1977:114). The 'meaningfulness' of a morph or allomorph can be of a lexical or grammatical nature. Zero morphs comply with the requirement of (grammatical) meaningfulness, even though they do not have a physical realization. Empty morphs, on the other hand, do have a physical shape, but they do not realize any morpheme, i.e. they have no meaning attached to them. 
In contrast to zero morphs, empty morphs do not enter into any allomorphic relations. They are segments which are mechanically employed in certain environments and conditions and they do not make any lexical or grammatical contribution.

It is clear that the traditional definitions of a morpheme as the smallest unit of form and meaning and of the morph as a meaning-bearing physical representation of a morpheme are challenged by the recognition of zero and empty morphs. In the case of zero morphs, there is an absence of a phonological manifestation, while in the case of empty morphs there is an absence of meaning. The fact that neither kind of morph complies simultaneously with both the requirement of a physical representation and the requirement of a meaning has been responsible for their dubious status. However, this has not kept morphologists from resorting to these terms as useful constituents in their analyses, especially if the criteria for morphs are extended to accommodate morphs with no overt phonemic material or segments which are nonmorphemic.

\section{References:}

Anderson, S.R. 1992. A-morphous morphology. Cambridge: Cambridge University Press.

Bauer, L. 1992. Introducing linguistic morphology. Edinburgh: Edinburgh University Press.

Brown, K. \& Miller, J. 1980. Syntax: A linguistic introduction to sentence structure. London: Hutchinson.

Brown, K. \& Miller, J. 1991. Syntax: A linguistic introduction to sentence structure. $2^{\text {nd }}$ ed. London: Harper Collins Academic.

Carstairs, A. 1987. Allomorphy in inflection. London, New York: Croom Helm.

Ferreira, J.A. 1968. Morfofonemiese aanpassings in die Sothotale. Taalfasette 5:31-47. Pretoria: J.L. van Schaik.

Hockett, C.F. 1947. Problems of morphemic analysis. Language 23:229-242. Reproduced in Joos (ed.) 1963.

Joos, M. (ed.) 1963. Readings in linguistics. $3^{\text {rd }}$ ed. New York: American Council of Learned Societies.

Katamba, F. 1993. Morphology. London: Macmillan.

Lockwood, D.G. 1993. Morphological analysis and description: A realizational approach. Tokyo, Dallas: International Language Sciences Publishers.

Lyons, J. 1968. Introduction to theoretical linguistics. Cambridge: Cambridge University Press.

Matthews, P.H. 1972. Inflectional morphology: A theoretical study based on aspects of Latin verb conjugation. Cambridge: Cambridge Univeristy Press.

Nida, E.A. 1948. The identification of morphemes. Language 24:255-271. Reproduced in Joos (ed.) 1963.

Okoth Okombo, D. 2000. Building techniques in African voices: An introduction to the languages and linguistics of Africa, edited by V. Webb \& Kembo-Sure. Oxford: Oxford University Press: 197-219.

Pearson, B.L. 1977. Introducing linguistic concepts. New York: Alfred A. Knopf.

Pike, K.L. \& Pike, E.G. 1977. Grammatical analysis. Publications in Linguistics 53. Dallas, Texas: Summer Institute of Linguistics.

Spencer, A. 1991. Morphological theory: An introduction to word structure in generative grammar. Oxford: Blackwell. 
Copyright of South African Journal of African Languages is the property of University of Port Elizabeth, Department of African Languages and its content may not be copied or emailed to multiple sites or posted to a listserv without the copyright holder's express written permission. However, users may print, download, or email articles for individual use. 